\title{
Particle swarm optimization for airlines fleet assignment
}

\author{
Abdallah A. Abouzeid, Mostafa Mohei Eldin, Mohammed Abdel Razek \\ Mathematics Department, Faculty of Science, Al Azhar University, Egypt
}

\section{Article Info}

Article history:

Received Nov 29, 2020

Revised Mar 4, 2021

Accepted Mar 12, 2021

Keywords:

Airline schedule

Artificial intelligence

Fleet assignment

Mixed integer programming

Particle swarm optimization

\begin{abstract}
Airline fleet assignment is the process of assigning aircraft types to scheduled flight legs in order to minimize operating cost and achieve maximize revenue, while satisfying a set of constraints. This paper formulates the fleet assignment problem for airlines that optimization goal is to minimize the total assignment cost. Particle swarm optimization (PSO) proposed to solve this model. The model successfully applied to Egyptair airline dataset using the particle swarm optimization and mixed integer programming. The proposed method compared with mixed integer programming and current Egyptair assignment methodology. The results showed that the particle swarm optimization is the best method for the Egyptair fleet assignment process. The solution quality is better than mixed integer programming and Egyptair assignment methodology where we saw a daily cost reduction with a percentage of $14.6 \%$ and $19.3 \%$ respectively.
\end{abstract}

This is an open access article under the CC BY-SA license.

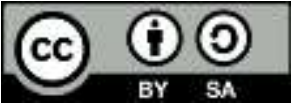

Corresponding Author:

Abdallah A. Abouzeid

Department of Mathematics

Al Azhar University

El Nasr Road, Naser City, Cairo, Egypt

Email: abdallah.ali@egyptair.com

\section{INTRODUCTION}

The fleet assignment problem (FAP) is the process of assigning each type of aircraft with different capacities to scheduled flights based on equipment functions and availability, operational costs, and potential revenue. The fleeting decision of an airline will greatly affect its revenue: assigning aircraft smaller than those needed to flight will result in customer loss due to insufficient capacity; allocating larger aircrafts will cause the seats to be unsold and possibly higher operating costs [1].

Egyptair is the largest airline company in Egypt; it has about 300 daily flights around the world and owns about 58 aircraft with different types. Egyptair has a major challenge in determining the optimum fleet type for all flight. Egyptair airlines assign a fixed type of aircraft for each flight leg according to its daily flight schedule because of the lack of intelligent model for fleet assignment that automate the assignment process.

Attempts to solve the problem of fleet assignment have used various optimization methods. Mixed-integer linear programming proposed for the formulation of the uniform fleet assignment problem and the results showed that using the heuristic mixed-integer programming method could produce good quality solutions [2]. Ant colony algorithm used to solve the fleet assignment problem by a focus on the optimal fleet assignment. The ant colony algorithm shows that dynamic demand consideration provides significantly outcomes including a decrease of operating expense with the rise in income [3]. Several recent studies [4-8] have suggested a solution for combining two or more sub problems. They combine airline fleet assignment with crew rostering, routing decisions, schedule design and maintenance. A nonlinear mixed integer-programming model and two heuristic methods to locate a cruise time control for the first time in an 
integrated model for aircraft fleeting [9]. Metaheuristic method that uses the variable neighborhood search (VNS) approach used to solve both fleet sizing problem and fleet assignment problem at the same time [10]. Deterministic linear programming (DLP) used for the historical development to overbooking and the consideration of flexible products as well as further applications [11]. The multi-criteria method used to solve the fleet assignment problem by minimizing the emission cost or maximizing the profit as an objective function [12]. Some of researchers use data of 22 aircraft types from 15 major US airlines to prototype the financial and operating data as an optimize aircraft selection [13]. Other researchers suggests that load factor, aircraft utilization, and aircraft size had influence over determining the operating cost of an airline [14]. On the other hand, in [15] show that the intelligent transportation solution for advanced fleet assignment can improve an airline's market benefit and increase customer satisfaction as well. The research analyzes a new airline stochastic fleet assignment problem with arbitrary passenger requirements in risk aversion. It showed a two-stage stochastic mixed-integer programming model for risk aversion. It starts with tactic level decisions: assigning aircraft families to flight legs. In the second stage, an algorithm used to assign aircraft types to flight legs. A parallel master-slave genetic algorithm (PMS-GA) used for solving the integrated flight schedule design and fleet assignment problem with demand recapture [16]. Nowadays, Artificial intelligence techniques have an effective role in enhancing companies, governments and in community development. Artificial intelligence techniques try to simulate human behavior. Compared with existing conventional techniques, they supply a better, faster, and more accurate solution to optimization problems. Artificial intelligence techniques usually use multiple solutions to obtain the best solution [17].

In this paper, we formulate the fleet assignment problem for airlines. We propose one the artificial intelligence optimization techniques, which is particle swarm optimization (PSO) to solve the fleet assignment model for Egyptair airlines by using actual dataset. The formulating and solving the FAP will contribute in optimizing the aircraft assignment process for Egyptair airlines that minimizing the overall operating costs required for operating the different fleet types and maximizing the company profitability. In addition, this paper compares the performance and objective function value for PSO results with the mixed integer programming (MIP) method and Egyptair current assignment methodology.

\section{RESEARCH METHOD}

\subsection{Fleet assignment problem formulation}

The fleet assignment process is usually depending on the airline's flight network and it formed as a mixed integer program [18]. Two main trends were used when constructing networks: the use of arcs to represent connections (connected networks), and the use of arcs to represent flight segments (time-space networks). In essence, these two constructions are similar because they both ensure that the model adheres to the following main constraints:

- Cover constraints: to ensure that each flight leg is assigned to exactly one fleet type

- Balance constraints: for continuity of aircraft flow

- Availability constraints: to ensure that total assigned aircraft limits the available

For each fleet type there exist three types of connection arcs in the network, the first arc is the ground arc that represent the aircraft staying in the same station(airport) for a period of time. The second arc is flight arc that represent the flight leg. The third arc is wrap-around arc, which connects the last event of the day with the first event of the next day to ensure the continuity of the daily fleet assignment. The following model proposed by Hane et al. [19].

$$
\begin{aligned}
& \text { Objective function: Minimize } \sum_{l \in L} \sum_{f \epsilon F} \boldsymbol{G}_{f l} \boldsymbol{Z}_{f l} \\
& \text { Cover: } \sum_{f \in F}^{\text {Subject to }} Z_{f l}=1 \quad \forall l \epsilon L \text {, }
\end{aligned}
$$

Balance : $\sum_{o \epsilon S} Z_{\text {fost }}+g_{f s t^{-} t}-\sum_{d \epsilon S} Z_{f s d t}-g_{f t t^{+}}=0 \quad \forall\{f s t\} \epsilon N$,

Avalability: $\sum_{l \epsilon O(F)} Z_{f l}+\sum_{s \epsilon S} g_{f s t_{n} t_{1}} \leq A_{f} \forall f \epsilon F, Z$ binary, $g \geq 0$

where;

$S$ : set of stations in the network, indexed by $s, o$, or $d$

$F$ : set of fleet types, indexed by $f$

$L$ : set of flight legs scheduled, indexed by $l$ or $\{o d t\}$, where $o, d \epsilon S$ and $t$ denotes the time when the flight

$N$ : set of nodes in the network, indexed by $\{f s t\}$, where $f \in F, s \in S$, and $t$ denotes the event time 
$O(f)$ :set of arcs for fleet type, $f$ that cross the aircraft count time-line, $f \epsilon F, l \in L$

The aircraft count time-line is the starting point for representing a series of events taking place in the network. The first node set after this timeline is represented as $\left\{f s t_{1}\right\}, f \in F, s \in S$, and the last node set of the day is represented as $\left\{f s t_{n}\right\}, f \in F, s \in S$.

$G_{f l}$ :cost of assigning fleet type $f$ to leg $l, f \epsilon F, l \in L$

$A_{f:}$ number of available aircraft for fleet type $f, f \in F$

$Z_{f l}=1$ if fleet $f$ assigned to leg $l, 0$ otherwise

$g_{f s t t^{\prime}}$ : flow of aircraft on the ground arc from node $\{f s t\} \in N$ to node $\left\{f s t^{\prime}\right\} \in N$ at station $s \in S$ in fleet

$t^{-}, t^{+}$: the time preceding and succeeding $t$, respectively, in the time-line

\subsection{PSO}

PSO is an algorithm proposed by Kennedy and Eberhart [20]. The PSO population, called cloud (or swarm), is composed by particles that are candidate solutions to the problem. Drawing an analogy with the flocks of birds, each particle acts as a bird from the flock looking for food. A swarm particles system begins the process of optimization with a population of random solutions, and searches for the optimal solution by updating the potential solutions through the iterations, the particles "fly" over the searching area looking for better solutions [21]. The PSO solutions cooperate among themselves and look for what called an optimal solution [22]. The velocity $V_{k}^{t}$ and position $X_{k}^{t}$ for a particle $k$ updated as following in $(2,3)$;

$$
\begin{aligned}
& \left.V_{k}^{t}=w V_{k}^{t-1}+c_{1} r_{1} \text { (pbest }_{k}-X_{k}^{t-1}\right)+c_{2} r_{2}\left(\text { gbest }-X_{k}^{t-1}\right) \\
& X_{k}^{t}=X_{k}^{t-1}+V_{k}^{t}
\end{aligned}
$$

where pbest $_{k}$ the personal best position found by the particle $\mathrm{k}$ and gbest the global best position of the swarm. $w$ The inertia factor that forces the particle to move in the same direction of the previous iteration. $c_{1}$ the cognitive factor that indicates the self-confidence of the particle. $c_{2}$ The social factor that forces the particle to follow the same way of the best particle of the swarm. $r_{1}, r_{2}$ are random numbers between $[0,1]$. To prevent the particle from driving too far away, we can adopt a velocity bound to keep it in the interval of $V_{\min }$ and $V_{\max }$, which are system parameters. All particles try to improve the performance of PSO by updating their velocity and position according to personal best and global best, and changing other parameters in different acceptable areas [23, 24].

\subsection{PSO representation for fleet assignment optimization}

In this section, we describe the representation of a PSO for solving airlines fleet assignment problem. The PSO classical approach needs some adjustments in order to be apply to optimization problems, such as redefining the particle in a discrete model, and adapting velocity operators [25]. Kennedy and Eberhart [26] encoded a particle $\mathrm{k}$ as a binary matrix and velocity defined as probability matrix in which the values can change from zero to one as the following:

$$
X_{k}^{t}=\left[\begin{array}{ccc}
x_{k, 11}^{t} & x_{k, 12}^{t} \ldots & x_{k, 1 n}^{t} \\
x_{k, 21}^{t} & x_{k, 22}^{t} & x_{k, 2 n}^{t} \\
\cdots & \cdots & \cdots \\
x_{k, m 1}^{t} & x_{k, m 2}^{t} & x_{k, m n}^{t}
\end{array}\right], x_{k, i j}^{t} \in[0,1] \quad, \quad V_{k}^{t}=\left[\begin{array}{ccc}
v_{k, 11}^{t} & v_{k, 12}^{t} \ldots & v_{k, 1 n}^{t} \\
v_{k, 21}^{t} & v_{k, 22}^{t} & v_{k, 2 n}^{t} \\
\cdots & \cdots & \cdots \\
v_{k, m 1}^{t} & v_{k, m 2}^{t} & v_{k, m n}^{t}
\end{array}\right], v_{k, i j}^{t} \in \mathcal{R}
$$

The representation of the fleet assignment will be achieved by using the binary representation of PSO described above by consider the rows in the particle matrix as the fleet type and columns as flights. The matrix $X_{k}^{t}$ represents a particle $\mathrm{k}$ made of $\mathrm{m} \times \mathrm{n}$ bits, which considered a position solution to the problem. When $x_{k, i j}^{t}=1$, this means that fleet type $i$ will be assigned to flight $j, x_{k, i j}^{t}=0$ otherwise. The particle movement was defined based on the probability of a position choosing one of two possible status, considering that the velocity is restricted to the interval $[0 ; 1]$. According to the authors' example, if $v_{k, i j}^{t}=0.20$, then there is a $20 \%$ chance that the bit $x_{k, i j}^{t}$ will become 1 , and $80 \%$ chance that it will become 0 . Table 1 and Table 2 describes an example for the representation of particle position and velocity used for solving the fleet assignment problem. velocity.

To keep the particle velocity values limited to interval $[0,1]$. In (4) used to normalize the particle 


$$
N\left(V_{k}^{t}\right)=\frac{1}{1+\exp \left(-V_{k}^{t}\right)}
$$

Then the particle position updated by adding the normalized particle velocity as in (4), so in (3) updated as the following:

$$
X_{k}^{t}=X_{k}^{t-1}+N\left(V_{k}^{t}\right)
$$

As seen in (1), the objective function used to evaluate the particle $\mathrm{k}$ to determine the optimal particle position, which is the fleet assignment solution. It calculated by summing the assignment cost $G(i, j)$ requird to assign fleet type $i$ to flight $j$ multiplied by particle position values $x_{k, i j}^{t}$ for particle $\mathrm{k}$ at iteration $t$ as in (6).

$$
C\left(X_{k}^{t}\right)=\sum_{i, j} G(i, j) \cdot x_{k, i j}^{t}
$$

Table 1. Representation of the particle position

\begin{tabular}{ccccccc}
\hline \multicolumn{7}{c}{ Flights } \\
\hline Fleet & 0 & 1 & 0 & 0 & 1 & 0 \\
Types & 0 & 0 & 1 & 0 & 0 & 1 \\
& 1 & 0 & 0 & 0 & 0 & 0 \\
& 0 & 0 & 0 & 1 & 0 & 0 \\
\hline
\end{tabular}

Table 2. Representation of the particle velocity

\begin{tabular}{lllllll}
\hline \multicolumn{7}{c}{ Flights } \\
\hline Fleet & 0.10 & 0.99 & 0.19 & 0.15 & 0.99 & 0.27 \\
Type & 0.09 & 0.23 & 0.99 & 0.23 & 0.14 & 0.80 \\
& 0.97 & 0.20 & 0.17 & 0.15 & 0.13 & 0.33 \\
& 0.12 & 0.17 & 0.18 & 0.75 & 0.26 & 0.29 \\
\hline
\end{tabular}

\subsection{Fleet assignment solution algorithm}

As we saw in section 2.3 and how represent the particle position, velocity and objective function for PSO to solve the fleet assignment problem. In addition, we formulate the problem in section 2.1 (1). Now we ready implement the solution algorithm [27]. Table 3 display the proposed algorithm for the solution of fleet assignment using PSO.

Table 3. Fleet assignment solution algorithm using PSO technique

Input: number of stations st, number of flights $n$, number of fleet types $m$, ground aircraft at each station $g_{\mathrm{f}}(m a t r i x$ of size $m * s t)$, maximum capacity for each fleet type $A_{\mathrm{f}}$ (matrix of size $m * 1$ ), available aircraft for each fleet type $A_{\mathrm{v}}$ (matrix of size $\left.m * 1\right)$, operating cost for each fleet type with different flights $G$ (matrix of size $m * n$ ), PSO parameters (swarmSize, number of iterations itr, $\left.w, c_{1}, c_{2}, r_{1}, r_{2}, V_{\min }, V_{\max }\right)$

Output: optimal particle position that satisfy minimum operating cost and meets all constraints as mentioned in equation 1 (the output is a matrix of size $m^{*} n$ )

Start

1. $t=0$

2. gbest $\longrightarrow$ binary matrix will all ones of size $m^{*} n$

3. for $\mathrm{k}=0$ to swarmsize- 1 do (Initialize the particles with random positions and velocities)

3.1. $\quad X_{k}^{0} \longrightarrow$ a random binary solution (matrix size of $\mathrm{m} * \mathrm{n}$ )

3.2. $V_{k}^{0} \longrightarrow$ a random velocity $\epsilon\left[V_{\min }, V_{\max }\right]$ (matrix size of $\mathrm{m}^{*} \mathrm{n}$ )

3.3. pbest $_{k} \longrightarrow X_{k}^{0}$

4. end for

5. $C($ gbest $)=\sum_{i, j} G(i, j) \cdot$ gbest $_{i, j}$ (total assignment cost for particle gbest, where gbest g $_{i, j}$ is is global best position values at iteration number 0 )

6. for $\mathrm{k}=0$ to swarmsize- 1 do

6.1. $C\left(X_{k}^{0}\right)=\sum_{i, j} G(i, j) \cdot x_{i, j}^{0}$ (total assignment cost for particle position $X_{k}^{0}$ where $x_{i, j}^{0}$ is the particle position values at iteration number 0 )

6.2. If $C\left(X_{k}^{0}\right)<C$ (gbest) then

6.2.1. gbest $\longrightarrow X_{k}^{0}$

6.2.2. $C($ gbest $)=C\left(X_{k}^{0}\right)$

6.3. End if

7. End for

8. while $t<i t r$ do

8.1. for $\mathrm{k}=0$ to swarmSize-1 do

8.1.1. $C\left(X_{k}^{t}\right)=\sum_{i, j} G(i, j) \cdot x_{i, j}^{t} \quad$ (total assignment cost for particle position $X_{k}^{t}$, where $x_{i, j}^{t}$ is the particle position values at iteration number $\mathrm{t}$ )

8.1.2. $C\left(\right.$ pbest $\left._{k}\right)=\sum_{i, j} G(i, j)$. pbest $_{i, j}$ (total assignment cost for best position, where pbest $_{i, j}$ is the particle best positon values at iteration number $\mathrm{t})$

8.1.3. if $\mathrm{C}\left(X_{k}^{t}\right)<\mathrm{C}\left(\right.$ pbest $\left._{k}\right)$ then

8.1.3.1. pbest $_{k} \longrightarrow X_{k}^{t}$

Indonesian J Elec Eng \& Comp Sci, Vol. 22, No. 1, April 2021 : 427 - 434 


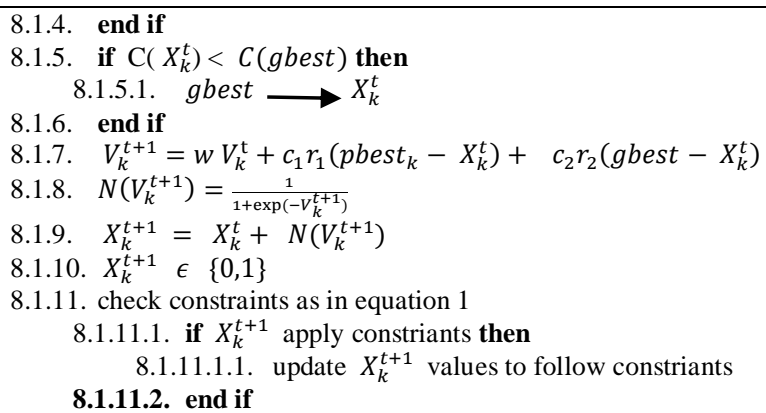

\subsection{Data acquisition}

Datasets collected from Egyptair airlines company for two years from 1/7/2017 until 30/6/2019. The data extracted from Egyptair accounting and costing system. The data attributes are Flight date, flight number, origin, and destination, assigned aircraft type, operating cost, number of KM flown, number of available seats, and number of passengers. For simplicity of fleet assignment implementation, we choose seven stations from Egyptair network. That is Cairo international airport (CAI) as the hub station and the spokes are Kuwait (KWI), New York (JFK), Frankfurt (FAR), London (LHR), Jeddah (JED) and Riyadh (RUH). The data set has 20671 of rows and nine columns for the specified seven stations above. Egyptair airlines have nine different category of aircraft types fly over the word. The fleet types are A320-232, A321-231, A330-200, A330-300, B737-800, B737-800NEW, B777-200, B777-300, and B787-900. Egyptair have $4,2,5,4,20,9,2,6$, and 6 from each type respectively. The specified seven stations have about 30 flights per day. Table 4 represent the sample of data for flights schedule in a day, in addation contains the corresponding assigned fleet type and its operating cost. The table contains the number of passengers and the distance flown.

Table 4. Sample of collected dataset for a day

\begin{tabular}{|c|c|c|c|c|c|c|c|}
\hline Flight No. & Origin & Destination & Assigned Aircraft & $\begin{array}{l}\text { Operating cost } \\
\text { (USD) }\end{array}$ & $\begin{array}{c}\text { number of KM } \\
\text { flown }\end{array}$ & $\begin{array}{c}\text { Number of } \\
\text { available seats }\end{array}$ & $\begin{array}{l}\text { Number of } \\
\text { passengers }\end{array}$ \\
\hline MS0610 & CAI & KWI & B737-800 & 5316 & 1601 & 144 & 85 \\
\hline MS0611 & KWI & CAI & B737-800 & 10728 & 1601 & 144 & 107 \\
\hline MS0612 & CAI & KWI & B737-800 & 5803 & 1601 & 144 & 119 \\
\hline MS0613 & KWI & CAI & B737-800 & 9785 & 1601 & 144 & 108 \\
\hline MS0620 & CAI & KWI & B737-800 & 5614 & 1216 & 144 & 127 \\
\hline MS0621 & KWI & CAI & B737-800 & 9465 & 1216 & 144 & 139 \\
\hline MS0647 & CAI & RUH & B737-800 & 3879 & 1216 & 144 & 82 \\
\hline MS0648 & RUH & CAI & B737-800 & 8792 & 1216 & 144 & 132 \\
\hline MS0649 & CAI & RUH & A330-200 & 15018 & 1216 & 268 & 180 \\
\hline MS0650 & RUH & CAI & A330-200 & 18616 & 1216 & 268 & 262 \\
\hline MS0651 & CAI & RUH & B737-800 & 5930 & 1216 & 144 & 117 \\
\hline MS0652 & RUH & CAI & A $330-200$ & 18096 & 1216 & 268 & 257 \\
\hline MS0661 & CAI & JED & B737-800 & 5124 & 1216 & 144 & 80 \\
\hline MS0662 & JED & CAI & B737-800 & 8989 & 1216 & 144 & 125 \\
\hline MS0663 & CAI & JED & A330-300 & 16838 & 1216 & 301 & 185 \\
\hline MS0664 & JED & CAI & A330-300 & 20377 & 1216 & 301 & 287 \\
\hline MS0665 & CAI & JED & B777-300 & 53550 & 3531 & 346 & 329 \\
\hline MS0666 & JED & CAI & B777-300 & 63648 & 3531 & 346 & 263 \\
\hline MS0671 & CAI & JED & B737-800 NEW & 26860 & 3531 & 154 & 139 \\
\hline MS0672 & JED & CAI & B737-800 NEW & 22982 & 3531 & 154 & 125 \\
\hline MS0673 & CAI & JED & B737-800 NEW & 17645 & 2921 & 154 & 128 \\
\hline MS0674 & JED & CAI & B737-800 NEW & 20709 & 2921 & 154 & 98 \\
\hline MS0777 & CAI & LHR & B777-300 & 150710 & 9010 & 346 & 319 \\
\hline MS0778 & LHR & CAI & B777-300 & 183501 & 9010 & 346 & 311 \\
\hline MS0779 & CAI & LHR & B777-300 & 28836 & 1601 & 346 & 227 \\
\hline MS0780 & LHR & CAI & B777-300 & 36397 & 1601 & 346 & 272 \\
\hline MS0785 & CAI & FRA & B737-800 & 2224 & 1216 & 144 & 120 \\
\hline MS0786 & FRA & CAI & B737-800 & 6279 & 1216 & 144 & 125 \\
\hline MS0985 & CAI & JFK & B737-800 & 6313 & 1216 & 144 & 120 \\
\hline MS0986 & JFK & CAI & B737-800 & 2496 & 1216 & 144 & 122 \\
\hline
\end{tabular}




\section{RESULTS AND DISCUSSION}

The proposed PSO algorithm described in section 2.4 for the solution of fleet assignment problem developed by authors using Python programming language. The developed model implemented and tested using Egyptair dataset specified in section 2.5. The developed model reads the dataset from an excel sheet. It extracts all required inputs and makes a suitable representation for the data to get the optimal solution for fleet assignment problem. On the other hand, we develop another model to solve the fleet assignment problem using other optimization technique, which is mixed integer programing (MIP). The developed model based on MIP solver implemented by google. We implement and test the model on the same dataset for Egyptair airlines. To measure the effectiveness and validity of PSO algorithm, results compared with other, MIP and current Egyptair assignment methodology. The criteria of performance considered were the quality of solutions (optimal total assignment cost). The percentage of improvement in total assignment cost computed as the following equation for the different methods [28]:

$$
\left(1-\frac{\text { Total asignment cost using the one method }}{\text { Total assignment cost using the other method }}\right) \times 100
$$

We use the following parameter values when using PSO. The inertia weight $\mathrm{w}=0.5$, cognitive and social factors $c_{1}=c_{2}=1$, swarm size $=1000$, the number of iterations $=10000$ and particle velocity bounds between 0 and 1.

For simplicity, we will display the PSO and MIP results for the specified stations mentioned in section 2.5 with detailed results for one day (01/01/2019). Table 5 displays the fleet assignment solution for scheduled flights for one day using PSO and MIP. The results compared to Egyptair assignment methodology. The results display that there are cost reduction when using MIP than Egyptair methodology by $5.5 \%$ or saving daily cost $43,814 \$$. If we use PSO, we have cost reduction by $19.3 \%$ than using Egyptair assignment methodology or we save daily cost $152,585 \$$. On the other hand when compare PSO with MIP technique, we find 14.6\% improvement or save daily cost 108,771\$. For other assignment, Table 6 displays the assignment cost comparison for Egyptair assignment methodology, MIP and PSO for seven days $(1 / 2 / 2019,1 / 3 / 2019,1 / 4 / 2019,1 / 5 / 2019,1 / 6 / 2019,1 / 7 / 2019$ and 1/8/2019).

Table 5. Egyptair fleet assignment solution and cost comparison for Egyptiar methodology, PSO and MIP for day $1 / 1 / 20109$

\begin{tabular}{|c|c|c|c|c|c|}
\hline $\begin{array}{l}\text { Flight } \\
\text { NO. }\end{array}$ & Origin & Destination & $\begin{array}{l}\text { Assigned fleet type by using } \\
\text { Egyptair method }\end{array}$ & $\begin{array}{c}\text { Assigned Fleet By } \\
\text { using MIP }\end{array}$ & Assigned Fleet by using PSO \\
\hline MS0610 & CAI & KWI & B737-800 & B737-800 & B787-900 \\
\hline MS0611 & KWI & CAI & B737-800 & B737-800 NEW & B737-800 \\
\hline MS0612 & CAI & KWI & B737-800 & B737-800 & B777-300 \\
\hline MS0613 & KWI & CAI & B737-800 & B737-800 & A330-300 \\
\hline MS0620 & CAI & KWI & B737-800 & B737-800 & A330-300 \\
\hline MS0621 & KWI & CAI & B737-800 & B737-800 & B777-200 \\
\hline MS0647 & CAI & RUH & B737-800 & B737-800 NEW & B777-300 \\
\hline MS0648 & RUH & CAI & B737-800 & B737-800 & B787-900 \\
\hline MS0649 & CAI & RUH & A330-200 & B737-800 & B777-300 \\
\hline MS0650 & RUH & CAI & A330-200 & B737-800 & A330-200 \\
\hline MS0651 & CAI & RUH & B737-800 & B737-800 & B777-300 \\
\hline MS0652 & RUH & CAI & A $330-200$ & B737-800 & A330-300 \\
\hline MS0661 & CAI & JED & B737-800 & B737-800 & A320-232 \\
\hline MS0662 & JED & CAI & B737-800 & B737-800 & A320-232 \\
\hline MS0663 & CAI & JED & A $330-300$ & B737-800 & B777-300 \\
\hline MS0664 & JED & CAI & A $330-300$ & B737-800 & A321-231 \\
\hline MS0665 & CAI & JED & B777-300 & B737-800 & B737-800 \\
\hline MS0666 & JED & CAI & B777-300 & B737-800 & B737-800 \\
\hline MS0671 & CAI & JED & B737-800 NEW & B737-800 NEW & B737-800 \\
\hline MS0672 & JED & CAI & B737-800 NEW & B737-800 & B737-800 \\
\hline MS0673 & CAI & JED & B737-800 NEW & B737-800 & A330-200 \\
\hline MS0674 & JED & CAI & B737-800 NEW & B737-800 & B737-800 \\
\hline MS0777 & CAI & LHR & B777-300 & B737-800 NEW & B737-800 \\
\hline MS0778 & LHR & $\mathrm{CAI}$ & B777-300 & B737-800 NEW & B737-800 \\
\hline MS0779 & CAI & LHR & B777-300 & B737-800 NEW & B787-900 \\
\hline MS0780 & LHR & CAI & B777-300 & B737-800 NEW & B787-900 \\
\hline MS0785 & CAI & FRA & B737-800 & B737-800 NEW & B787-900 \\
\hline MS0786 & FRA & CAI & B737-800 & B737-800 NEW & B787-900 \\
\hline MS0985 & CAI & JFK & B737-800 & B737-800 & B737-800 \\
\hline MS0986 & JFK & CAI & B737-800 & A330-200 & B777-200 \\
\hline \multicolumn{3}{|c|}{ Total assignment Cost (USD) } & 790,520 & 746,706 & 637,935 \\
\hline \multicolumn{3}{|c|}{ Cost Improvement (\%) } & & $\begin{array}{l}5.5 \% \text { than Egyptair } \\
\text { methodology }\end{array}$ & $\begin{array}{l}19.3 \% \text { than Egyptair } \\
\text { methodology } 14.6 \% \text { than MIP method }\end{array}$ \\
\hline
\end{tabular}


The results in Table 6 displays the effect on the assignment cost for the three methods. We choose these days to display a different number of flight schedule for the referred seven stations. Table 6 displays the total assignment cost per day for each methodology. We note that there are cost reduction for these days 314,907\$ when using MIP than Egyptair methodology. The cost reduction increases when using PSO we find $1,202,908 \$$ for seven days than using Egyptair methodology. When comparing PSO with MIP for the same period, we found a cost reduction of $888,001 \$$. Figure 1 displays the assignment cost comparison for the three techniques. The effect of the developed model is to obtain the optimal fleet assignment and automate the process of fleet assignment for Egyptair airlines instead of using fixed aircraft type for each flight leg. The model uses an intelligent method to solve the problem. The solution to the problem has a great effect on company revenue by decreasing the operating costs required for covering the scheduled flights with different aircraft types. We found that the PSO technique is the best technique for solving the fleet assignment for Egyptair airlines.

Table 6. Egyptair assignment cost comparison for company methodology, MIP and PSO

\begin{tabular}{ccccccccc}
\hline Method & \multicolumn{9}{c}{ Assignment Cost/Day } \\
& $1 / 2 / 2019$ & $1 / 3 / 2019$ & $1 / 4 / 2019$ & $1 / 5 / 2019$ & $1 / 6 / 2019$ & $1 / 7 / 2019$ & $1 / 8 / 2019$ & Total assignment_cost \\
\hline $\begin{array}{c}\text { Egyptair assignment } \\
\text { methodology }\end{array}$ & 768,751 & 983,683 & $1,025,752$ & 984,773 & $1,464,852$ & 832,752 & $1,005,532$ & $7,066,095$ \\
MIP & 725,000 & 901,252 & $1,002,375$ & 898,026 & $1,390,455$ & 830,860 & $1,003,220$ & $6,751,188$ \\
PSO & 670,327 & 780,780 & 899,744 & 780,845 & $1,200,405$ & 640,560 & 890,526 & $5,863,187$ \\
\hline
\end{tabular}

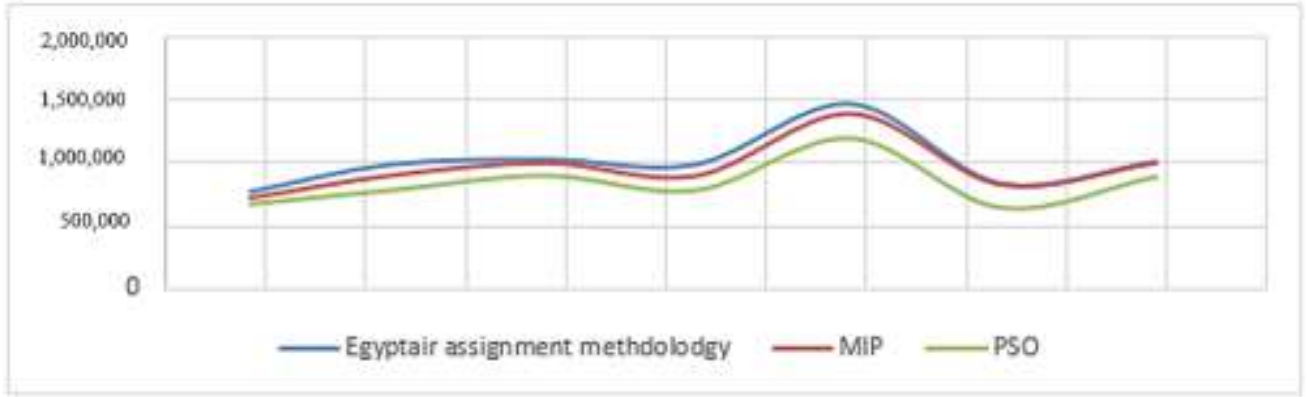

Figure 1. Egyptair assignment cost comparison for three techniques in seven days

\section{CONCLUSION AND FUTURE WORK}

Air transportation is the fastest long-distance transportation method. People prefer to use air transportation during holidays, business trips and almost all travel needs. Airlines faced with difficult and comprehensive issues such as fleet assignment, airline scheduling, and crew scheduling. Operating costs is the highest costs for airline companies that play a basic parameter in fleet assignment decision. The effective assignment of fleet types to flight segments is critical to airline planning. This paper formulated the fleet assignment problem for airlines that optimization goal is to minimize the total assignment cost. The problem solved by using one of the artificial intelligence optimization techniques, which is particle swarm optimization. To implement the model, we developed a python model for solving the fleet assignment problem using PSO and MIP methods. The model is tested and validated on Egyptair airlines actual dataset. The performance of PSO algorithm evaluated in comparison with MIP and Egyptair assignment methodology. The results showed that the PSO algorithm is the best solution. Where we see a daily cost reduction with percentage of $14.6 \%$ and $19.3 \%$ than MIP and Egyptair methodology respectively. To get more insights from results and its effects on Egyptair airlines. We test the program on flights for seven days. We solved the fleet assignment for Egyptair by available fleet types. We note that there are cost reduction for these days 314,907\$ when using MIP than Egyptair methodology. The cost reduction increases when using PSO we find 1,202,908\$ during seven days than using Egyptair methodology. A natural extension to this work would be applying another representation of particles for PSO as position permutations and compare it with the obtained results using the binary representation.

\section{REFERENCES}

[1] H. D. Sherali, E. Bish and X. Zhu, "Airline Fleet Assignment Concepts, Models, and Alogrithms," European Journal of Operational Research, vol. 172, pp. 1-30, 2006, doi: 10.1016/j.ejor.2005.01.056. 
[2] N. Belanger, G. Desaulniers, F. Soumis and J. Desrosiers, "Weekly airline fleet assignment with homogeneity," Transportation Research Part B, vol. 40, pp. 306-318, 2006, doi: 10.1016/j.trb.2005.03.004.

[3] R. Anzoom and M. Ahsan Akhtar Hasin, "Optimal Fleet Assignment Using Ant Colony Algorithm," in International Conference on Production and Operations Management Society (POMS), Peradeniya, Sri Lanka, 2018, doi: 10.1109/POMS.2018.8629468.

[4] C. Gao, E. Johnson and B. Smith, "Integrated airline fleet and crew robust planning," Transportation Science, vol. 43, no. 1, pp. 2-16, 2009, doi: 10.1287/trsc.1080.0257.

[5] M. Haouari, N. Aissaoui and F. Z. Mansour, "Network flow-based approaches for integrated aircraft fleeting and routing," European Journal of Operational Research, vol. 193, no. 2, pp. 591-599, 2009,

[6] A. Jebali and A. Diabat, "An integrated flight scheduling and fleet assignment problem under uncertainty," Computers \& Operations Research, vol. 100, no. 2, pp. 333-342, 2018, doi: 10.1016/j.cor.2017.08.014.

[7] A. Jamili, "A robust mathematical model and heuristic algorithms for integrated aircraft routing and scheduling, with consideration of fleet assignment problem," Journal of Air Transport Management, vol. 58, pp. 21-30, 2017, doi: 10.1016/j.jairtraman.2016.08.008.

[8] D. T. Sanchez, B. Boyacı and K. G. Zografos, "An optimisation framework for airline fleet maintenance scheduling with tail assignment considerations," Transportation Research Part B: Methodological, vol. 133, pp. 142-164, 2020, doi: $10.1016 /$ j.trb.2019.12.008.

[9] H. Gürkan, S. Gürel and M. S. Aktürk, "An integrated approach for airline scheduling, aircraft fleeting and routing with cruise speed control," Transportation Research Part C, vol. 68, pp. 38-57, 2016, dooi: 10.1016/j.trc.2016.03.002.

[10] S. Dožić, A. Jelović, M. Kalić and M. Čangalović, "Variable Neighborhood Search to solve an airline fleet sizing and fleet assignment problem," Transportation Research Procedia, vol. 37, pp. 258-265, 2019, doi: 10.1016/j.trpro.2018.12.191.

[11] W. Gaul and C. Winkler, "Aviation Data Analysis by Linear Programming in Airline Network Revenue Management," in Studies in Classification, Data Analysis, and Knowledge Organization, 2019.

[12] Q. Ma, H. Song and W. Zhu, "Low-carbon airline fleet assignment: A compromise approach," Journal of Air Transport Management, vol. 68, pp. 86-102, 2018, doi: 10.1016/j.jairtraman.2017.04.005.

[13] Y. Park and M. E. O'Kelly, "Examination of cost-efficient aircraft fleets using empirical operation data in US aviation markets," Jour. Of Air Trans. Man, vol. 69, pp. 224-234, 2018, doi: 10.1016/j.jairtraman.2017.02.002.

[14] J. Zuidberg, "An econometric analysis of the factors affecting aircraft operating costs," Jour. Of Air Trans. Man, vol. 40, pp. 86-95, 2014, doi: 10.1016/j.jairtraman.2014.06.007.

[15] M. Liu, B. Liang, F. Zheng and F. Chu, "Stochastic Airline Fleet Assignment With Risk Aversion," IEEE Transactions on Intelligent Transportation Systems, vol. 20, no. 8, pp. 3081-3090, Aug 2019, doi: 10.1109/TITS.2018.2871969.

[16] E. Khanmirza, M. Nazarahari and M. Haghbeigi, "A heuristic approach for optimal integrated airline schedule design and fleet assignment with demand recapture," Applied Soft Computing, vol. 96, 2020, doi: 10.1016/j.asoc.2020.106681.

[17] Badar, B. Umre and A. S. Junghare, "Study of Artificial Intelligence Optimization Techniques applied to Active Power Loss Minimization," in International Conference on Advances in Engineering \& Technology, 2014.

[18] Y. Ozdemir, H. Basligil and K. Nalbant, "Optimization of Fleet Assignment: A Case Study in Turkey," An International Journal of Optimization, vol. 2, no. 1, pp. 59-71, 2012, doi: 10.11121/ijocta.01.2012.0050.

[19] C. Hane, C. Barnhart, E. Johnson, R. Marsten, G. Nemhauser and G. Sigismondi, "The fleet assignment problem: Solving a large-scale integer program," Mathematical Programming, vol. 70, pp. 211-232, 1995.

[20] J. Kennedy, and R. C. Eberhart, "Particle swarm optimization," Proceedings of the IEEE International Conference on Neural Networks, 1995, doi: 10.1109/ICNN.1995.488968.

[21] X. Hu, R. Eberhart and Y. Shi., "Swarm intelligence for permutation optimization: a case study on n-queens problem," in In Proceedings of the IEEE Swarm Intelligence Symposium 2003, 2003, doi: 10.1109/SIS.2003.1202275.

[22] A. Banks, J. Vincent and C. Anyakoha, "A review of particle swarm optimization. Part I: background and development," Natural Computing, vol. 6, no. 4, pp. 467-484, 2007.

[23] E. Karunarathne, J. Pasupuleti, J. Ekanayake and D. Almeida, "Comprehensive learning particle swarm optimization for sizing and placement of distributed generation for network loss reduction," Indonesian Journal of Electrical Engineering and Computer Science, vol. 20, no. 1, pp. 16-23, 2020, doi: 10.11591/ijeecs.v20.i1.pp16-23.

[24] M. Rasheed, R. Omar, M. Sulaiman and W. Abd Halim, "A modified cascaded h-bridge multilevel inverter based on particle swarm optimisation (PSO) technique," Indonesian Journal of Electrical Engineering and Computer Science, vol. 16, no. 1, pp. 41-51, 2019, doi: 10.11591/ijeecs.v16.i1.pp41-51.

[25] L. H., G. L. and P. Q., "A hybrid particle swarm optimization with estimation of distribution algorithm for solving permutation flowshop scheduling problem," Expert Systems with Applications, vol. 38, no. 4, p. 4348-4360, 2011, doi: /10.1016/j.eswa.2010.09.104.

[26] R. Eberhart and J. Kennedy, "New Optimmizer Using Particles Swarm Theory," Sixth International Symposium on Micro Machine and Human Science, IEEE, 1995, pp. 39-43, doi: 10.1109/MHS.1995.494215.

[27] L. J. Pierobom, M. R. Delgado and C. A. Kaestner, "Particle swarm optimization applied to task assignment problem," in 10th Brazilian Congress on Computational Intelligence, Brazil, 2011, doi: 10.21528/CBIC2011-16.4.

[28] Aa. Salman, A. Ahmad and S. Al-Madani, "Particle swarm optimization for task assignment problem," Microprocessors and Microsystems, vol. 26, no. 8, pp. 363-371, 2002, doi: 10.1016/S0141-9331(02)00053-4. 